Check for updates

Cite this: Mater. Adv., 2020 1,1675

Received 10th July 2020, Accepted 24th August 2020

DOI: $10.1039 / \mathrm{d} 0 \mathrm{ma} 00498 \mathrm{~g}$

rsc.li/materials-advances

\title{
Acrylate-gelatin-carbonated hydroxyapatite (cHAP) composites for dental bone-tissue applications
}

\section{Introduction}

With a growing world population, bone defects resulting from trauma, disease, or surgery are a significant worldwide problem. The global market of dental bone grafts and substitutes is projected to reach USD 1.0 billion by 2026, and 82 countries across the world are anticipated to have more than $20 \%$ of their populations in the elderly category by $2050,{ }^{1}$ and the global demand for bone grafts will be exceedingly high.

The material used as a bone scaffold must satisfy a number of requirements, including biocompatibility, biodegradation with negligible toxicity, appropriate porosity, and mechanical properties, and the ability to integrate with biological molecules

\footnotetext{
${ }^{a}$ Institute of Chemistry, Faculty of Chemistry and Geosciences, Vilnius University, Naugarduko 24, Vilnius LT-03225, Lithuania

${ }^{b}$ Private Dental Clinic RG Clinic, Kalvariju 137D-5, Vilnius LT-08221, Lithuania ${ }^{c}$ Department of Ocean Operations and Civil Engineering, Faculty of Engineering, Norwegian University of Science and Technology, Larsgårdsvegen 2, 6025 Ålesund, Norway

${ }^{d}$ Wood Science and Engineering, Department of Engineering Sciences and Mathematics, Luleå University of Technology, Forskargatan 1, SE-931 87 Skellefteå, Sweden.

E-mail: edita.garskaite@ltu.se; Tel: +46-72-2332094
}

or cells to regenerate tissue. ${ }^{2-7}$ Currently due to clinical predictability, the autologous bone or autograft is regarded as the "gold standard" for bone defect repair, but complications such as limited supply and donor-site morbidity are stimulating the development of bone substitutes of biological and synthetic origin..$^{8-12}$

Scaffolds made of synthetic polymers have been studied for bone-tissue engineering applications as they are able to produce materials that exhibit both toughness and plasticity, the most commonly used synthetic polymers are polylactic acid (PLA), polyglycolic acid (PGA), copolymers of PLA and PGA, polycaprolactone, and polymethylmethacrylate (PMMA). ${ }^{13-20}$ Due to their different mechanical properties and degradation rates, as well as the absence of osteoconductivity (supporting bone growth and encouraging the ingrowth of surrounding bone), the synergistic combination of calcium phosphate (CaP) as an osteoconductive bioabsorbable ceramic in a polymeric matrix has been explored. ${ }^{21-23}$ These inorganic-organic hybrids possess an advantage over single components as their interactions at a molecular level can provide interdependent properties while acting as a single-phase material.

The most frequently investigated synthetic CaPs are hydroxyapatite (HAP), calcium-deficient hydroxyapatite (CDHA), tricalcium 
phosphate (TCP) and biphasic calcium phosphate (BCP) ${ }^{24-26}$ The advantages and disadvantages of these bioceramics with high or low resorption or dissolution rates have been broadly discussed, and some of these materials are able under certain conditions to transform from one to another. ${ }^{27}$ For example, $\alpha$-TCP is much more reactive than $\beta$-TCP in aqueous solutions and can easily be hydrolysed with the formation of CDHA, which is similar to HAP and resembles carbonated hydroxyapatite (cHAP), the mineral component of natural bones and teeth. ${ }^{28}$

In addition to its chemical composition, the surface topography and porosity are extremely important features determining the extend of scaffold integration with the host bone. It has been demonstrated that the curvature of the surface as well as the size (micro/macro) and geometry of the pores determine the cellular responses such as their adhesion, penetration, differentiation, nutrition diffusion, and ultimately bone ingrowth. ${ }^{5-7,29-31}$ For this reason, a variety of techniques have been used to create three-dimensional (3D) composite scaffolds with different porosities and surface characteristics, of which gas-foaming, ${ }^{32,33}$ porogen leaching ${ }^{34}$ microsphere sintering ${ }^{35}$ and phase separation/freezecasting, ${ }^{36-38}$ electrospinning ${ }^{39}$ can be mentioned. 3D printing technology makes it possible to produce scaffolds with a high degree of complexity and precision at a micron level, ${ }^{40-42}$ and a selective laser sintering (SLS) method has also been used to produce 3D structures with well-defined interconnected pores. ${ }^{43}$

Most synthetic polymers are highly hydrophobic and the incorporation of a biological polymer, such as collagen, gelatin or hyaluronic acid is a popular method to alter the physicochemical properties of the matrix and promote biological response. ${ }^{7,44-47}$ These polymers also have the potential to be used as smart materials, with an ability to respond to changes in physiological parameters and exogenous stimuli. ${ }^{48}$ Gelatin, derived from collagen, is a particularly attractive biomolecule for bone-scaffold engineering because of its lower cost, commercial availability, and well-defined physicochemical properties. ${ }^{49}$ Different applications in bone and improved functionalities of scaffolds have been demonstrated. Kumar Teolia et al. have shown, for example, that the incorporation of gelatin into bone cement material enhances its osteoconductive properties. ${ }^{50}$ It has also been shown that $3 \mathrm{D}$ printed scaffolds containing nanoapatite and alginate/gelatin polymers can promote the positive proliferation and osteogenic differentiation of stem cells. ${ }^{42}$

The development of new bone-replacement materials and biofunctionalization strategies thus requires an accurate assessment of the scaffold structure. An established technique that provides three-dimensional information is computed tomography (CT),${ }^{51-53}$ which is non-destructive and is used for imaging of internal structures based on the density distribution in the materials microstructure. CT can provide a fast quantification of scaffold density which is highly correlated to properties such as strength, stiffness, and toughness. ${ }^{54,55}$ CT has been used extensively to quantify the $3 \mathrm{D}$ geometry of bone, to determine the bone mineral density and to measure the mean degree of mineralization. ${ }^{50,51,56}$

In the present work, we describe the fabrication of multicomposite scaffolds consisting of DPHA/EGDMA, cHAP and gelatin that due to material-specific characteristics have a potential in clinical bone defect repair applications. The cHAP powders were synthesized by precipitation and annealing at $800{ }^{\circ} \mathrm{C}$. The phase composition and crystallinity of the bioceramics were evaluated by XRD and FTIR spectroscopy, and the morphology and elemental composition of the scaffolds were studied using SEM/EDS. Thermogravimetic analyses (TGA, DSC) and FTIR-ATR spectroscopy have been used for additional characterization, and the density of the scaffolds and the distribution of cHAP within the polymeric matrix have been assessed using CT and conventional dental radiography, respectively. Finally, the hydrophilicity of the grafted composites was evaluated by measuring the contact angle of water tinted with methylene blue.

\section{Experimental}

\section{1. cHAP synthesis}

Carbonated hydroxyapatite was synthesized as previously reported, ${ }^{57}$ where calcium acetate hydrate $\left(\mathrm{Ca}\left(\mathrm{CH}_{3} \mathrm{COO}\right)_{2} \cdot \mathrm{H}_{2} \mathrm{O}, \geq 99 \%\right.$, Roth) $(5.285 \mathrm{~g}, \quad 0.03 \mathrm{~mol})$ and diammonium hydrogen phosphate $\left(\left(\mathrm{NH}_{4}\right)_{2} \mathrm{HPO}_{4}, 99.9 \%\right.$, Alfa Aesar $)(2.377 \mathrm{~g}, 0.018 \mathrm{~mol})$ were first dissolved in separate beakers, each in $25 \mathrm{~mL}$ of distilled water. To each of these solutions, $25 \mathrm{~mL}$ of $6 \%$ polyethylene glycol $\left(\mathrm{H}\left(\mathrm{OCH}_{2}-\mathrm{CH}_{2}\right)_{n} \mathrm{OH}\right.$, PEG, 4600, Aldrich) aqueous solution was then added as a crosslinking agent and the mixtures were stirred for $30 \mathrm{~min}$ at $55-60{ }^{\circ} \mathrm{C}$, after which aqueous ammonia ( $\mathrm{NH}_{3}$ (aq.), 32\% aq. sol., Merck), was added to $\mathrm{pH} 11$. These mixtures were then stirred for $20 \mathrm{~min}$ at $65-80{ }^{\circ} \mathrm{C}$ and finally mixed together (Ca: $\mathrm{P}$ ratio of 1.67 ). The white $\mathrm{Ca}-\mathrm{P}-\mathrm{O}$ precipitate was then stirred for $30 \mathrm{~min}$ in a beaker covered with a watch glass and latex cover to prevent evaporation of ammonia, after which the suspension was evaporated at $80-100{ }^{\circ} \mathrm{C}$ leaving a Ca-P-O gel. The gel was dried at $150{ }^{\circ} \mathrm{C}$ for $24 \mathrm{~h}$, and samples were calcined at 400 , 600,680 and $800^{\circ} \mathrm{C}$ for $5 \mathrm{~h}$ in air (with the temperature increasing at a rate of $1{ }^{\circ} \mathrm{C} \min ^{-1}$ from $25{ }^{\circ} \mathrm{C}$ ) with intermediate grinding between each calcination procedure.

\subsection{Preparation of multi-composite scaffolds}

The starting components for the multi-composite scaffolds were dipentaerythritol hexa-acrylate (DPHA, Miramer (M600), $\mathrm{C}_{25} \mathrm{H}_{32} \mathrm{O}_{12}$, Rahn USA Corp.) (35.2 g, $0.067 \mathrm{~mol}$ ), ethylene glycol dimethacrylate (EGDMA, $\mathrm{C}_{10} \mathrm{H}_{14} \mathrm{O}_{4}$, Merck) $(8.8 \mathrm{~g}, 0.044 \mathrm{~mol})$, (diphenyl-phosphinyl)-(2,4,6-trimethylphenyl)methanone (Genucure TPO, $\mathrm{C}_{22} \mathrm{H}_{21} \mathrm{O}_{2} \mathrm{P}$, Rahn USA Corp.) $(0.2 \mathrm{~g}, 0.0006 \mathrm{~mol})$, and gelatin powder.

The monomers DPHA and EGDMA were first mechanically mixed in a beaker (weight ratio of DPHA: EGDMA $4: 1$ ). Gelatin, a biopolymer used as a porosity agent, was then added to the mixture and further mixed until a homogeneous composite mixture was obtained. The weight ratios of DPHA-EGDMA: gelatin were 50:50 (10 g: $10 \mathrm{~g}), 75: 25(15 \mathrm{~g}: 5 \mathrm{~g})$ and $95: 5(19 \mathrm{~g}: 1 \mathrm{~g})$ and these are designated as Mix-1, Mix-2 and Mix-3, respectively. cHAP powders heated at $800{ }^{\circ} \mathrm{C}$ were then introduced into the mixtures as a filler. The Mix-1 mixture exhibited a low viscosity and a larger amount of cHAP therefore was added (weight ratios 
of Mix-1: cHAP, and of Mix-2: cHAP and Mix-3: cHAP were $2.1 \mathrm{~g}$ : $1 \mathrm{~g}$, and $1.5 \mathrm{~g}: 1 \mathrm{~g}$, respectively). Subsequently, $0.02 \mathrm{~g}$ of the photoinitiator TPO was added to all three systems and the resultant mixtures were vigorously mixed for 5 min using a Heidolph silent crusher $\mathbf{M}$ homogenizer. Finally, the mixtures were weighed in $0.5 \mathrm{~g}$ portions and the pellets of $c a .0 .5 \mathrm{~cm}$ in diameter and $0.1-0.2 \mathrm{~cm}$ in thickness were placed on the silicon plate and illuminated with a dental lamp (UV irradiation at a wavelength of $365 \mathrm{~nm}$ ) at room temperature for $5 \mathrm{~min}$ to achieve photopolymerization. The polymerized material was then further cured at $40{ }^{\circ} \mathrm{C}$ for $24 \mathrm{~h}$. The composites were designated according to the acrylate and gelatin ratio within the initial organic matrix, i.e. acrylate(50\%)-gelatin(50\%)-cHAP, acrylate(75\%)gelatin(25\%)-cHAP, acrylate(95\%)-gelatin(5\%)-cHAP.

\subsection{Characterization}

Thermogravimetric analysis (TG) and differential scanning calorimetry (DSC) of the $\mathrm{Mg}-\mathrm{Ca}-\mathrm{P}-\mathrm{O}$ gel were performed using a PerkinElmer STA 6000 Simultaneous Thermal Analyzer. Dried samples of $\sim 5-10 \mathrm{mg}$ were heated from 25 to $900{ }^{\circ} \mathrm{C}$ at a rate of $10{ }^{\circ} \mathrm{C} \min ^{-1}$ in dry flowing air $\left(20 \mathrm{~mL} \mathrm{~min}^{-1}\right)$. The phase composition of the annealed cHAP powders was studied by X-ray diffraction (XRD, Rigaku, MiniFlex II, $\mathrm{Cu}-\mathrm{K} \alpha$ radiation, $\lambda=$ $0.1542 \mathrm{~nm}, 40 \mathrm{kV}, 100 \mathrm{~mA}, 2 \theta=10-60^{\circ}$ ), and crystalline phases were identified by comparing the diffraction patterns obtained with those in the database provided by JCPDS (Joint Committee on Powder Diffraction Standards). Rietveld analysis for XRD pattern $\left(2 \theta=10-70^{\circ}\right)$ was performed using Match! and FullProff software. The average crystallite size was estimated by the Scherrer equation, $d_{\mathrm{XRD}}=K \lambda / \beta \cos \theta$, using the full-width at half maximum (FWHM) of the (002), (222) and (004) Bragg reflections. Morphological features and elemental distribution were evaluated using field emission scanning electron microscopy (FE-SEM, SU70, Hitachi, $5.0 \mathrm{kV}$ acc. voltage) and a tabletop scanning electron microscope (SEM, TM3000, Hitachi, $15.0 \mathrm{kV}$ acc. voltage) equipped with an energy dispersive X-ray spectrometer (EDS) using INCA software (Oxford Instruments). Infrared spectra of the ground composite powders were recorded with a Fourier transform infrared (FTIR) spectrometry (Frontier FTIR, PerkinElmer, ZnSe/Diamond ATR crystal, DTGS detector, 4000-600 $\mathrm{cm}^{-1}, 4$ scans). The optical contact angle measurements were performed using DataPhysics OCA 15EC system ( $n=4$ for each multi-composite scaffold). Raman spectra were recorded at room temperature using combined Raman and scanning near field optical microscope (SNOM) WiTec Alpha $300 \mathrm{R}$ equipped with $532 \mathrm{~nm}$ excitation laser source.

\subsection{Computed tomography (CT) and conventional radiography}

A medical CT-scanner Siemens Somatom Emotion Duo with a field of view of $500 \times 500 \mathrm{~mm}^{2}$ represented in a grayscale $512 \times$ 512 pixel image, which gave a resolution of $0.98 \mathrm{~mm}$, was used to evaluate the density of the cHAP-acrylate-gelatin composites. In a CT, one pixel represents a three-dimensional entity (voxel) of the material scanned with the dimensions of the pixel and the thickness of the scanning beam (the beam depth).
In order to evaluate average density of the composites from the CT-image, the images were converted into a binary image by using the image processing method thresholding. This method replaces each pixel in the image with a black pixel if it's intensity is less than a fixed constant, or with a white pixel if it's intensity is greater than that constant. A black pixel is represented by the value 0 , and white pixel is represented by the value 1 . In this analysis, the fixed constant was set to $100 \mathrm{~kg} \mathrm{~m}^{-3}$. When the composite is isolated by the thresholding method, every index of nonzero elements is found in the binary image. These indices are then used to obtain the corresponding pixels in the original CT image to calculate the average density $\left(\mathrm{kg} \mathrm{m}^{-3}\right)$ by following equation:

$$
\bar{\rho}=\frac{1}{n} \sum_{i=1}^{n} \rho_{i}
$$

where $n$ is the number of pixels and $\rho_{i}$ is the density value in the specific pixel (voxel). A beam energy level of $80 \mathrm{kV}$ and $110 \mathrm{kV}$ was used to scan the specimens (a total of 24 scans with a resolution of $1 \mathrm{~mm}$ over a total length of $2 \mathrm{~cm}$ ). The X-ray beam acceleration voltages in the X-ray tube of $80 \mathrm{kV}$ and $110 \mathrm{kV}$ provide average photon energies of $52 \mathrm{keV}$ and $63 \mathrm{keV}$, respectively. ${ }^{58}$ Matlab software was used to process $2 \mathrm{D}$ images of the composite pellets.

Cone beam computed tomography (CBCT) was performed using Morita veraview R100 (Japan) system with a loading factor of $90 \mathrm{kV}$ and $5 \mathrm{~mA}$.

Satelec X-Mind DC (Acteon, UK) intra-oral X-ray unit (X-ray tube: New Toshiba DG 073B DC tube, voltage: $60-70 \mathrm{kV}$, anode current: $4-8 \mathrm{~mA}$, focal spot: $0.7 \mathrm{~mm}$, total filtration: equivalent to $2 \mathrm{~mm} \mathrm{Al} \mathrm{at} 70 \mathrm{kV}$, tube inherent filtration: equivalent to $0.8 \mathrm{~mm} \mathrm{Al}$ at $70 \mathrm{kV}$, long cone: focus to cylinder tip distance $=$ $31 \mathrm{~cm}$, exposure time of $0.02-3.2 \mathrm{~s}$ ) was used to take radiographic images of the scaffolds.

\section{Results and discussion}

\subsection{CHAP characterization}

The XRD pattern of $\mathrm{Ca}-\mathrm{P}-\mathrm{O}$ gel powders annealed at $800{ }^{\circ} \mathrm{C}$ presented in Fig. 1, show that powders produced at $800{ }^{\circ} \mathrm{C}$ are already crystalline with well resolved diffraction peaks from the Bragg diffraction conditions for HAP [PDF\# 00-3553] (hexagonal crystal system, space group of $\left.P 6_{3} / \mathrm{m}\right)$. In addition, Rietveld analysis was performed. The calculated lattice parameters $(a=$ 9.4227(8) $\AA$ and $c=6.8843(6) \AA$ ) are consistent with the parameters found in literature for HAP. ${ }^{59}$ Rietveld refinement for XRD pattern (Fig. 2) showed the elongation of reflection at $2 \theta=45.8^{\circ}$ for (002) indicating possible elongation of crystals along the $\langle 002\rangle$ plane. This agrees with our previous study where cHAP crystals produced from solutions containing polyethylene glycol exhibited slight lengthening compare to those produced from solutions containing polyvinyl alcohol. ${ }^{57}$ The average crystallite size was estimated to be $32 \pm 5 \mathrm{~nm}$. Small crystal sizes are linked to the relatively high solubility of biological apatites with respect to stoichiometric HAP, ${ }^{28}$ which probably 

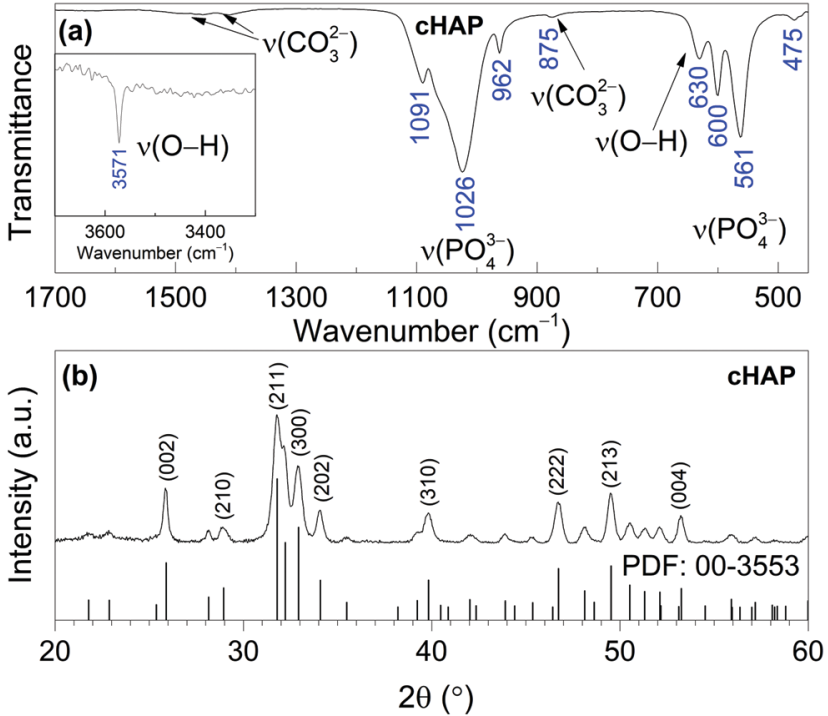

Fig. 1 FT-IR spectrum (a) and XRD pattern (b) of cHAP powders calcined at $800{ }^{\circ} \mathrm{C}$.

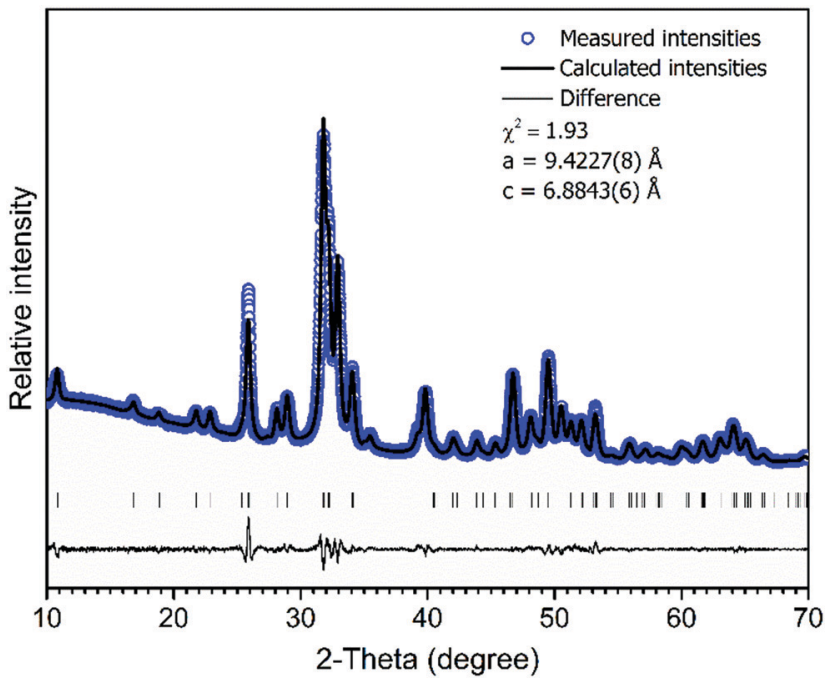

Fig. 2 Rietveld fit to CHAP powders XRD data. Experimental (O) and calculated (-) patterns are shown along with the difference curve (-) and (1) Bragg positions.

alters the nanoscale surface structure, increasing the surface area and surface wettability of the scaffold, offering favourable conditions for cell adhesion.

The FT-IR spectrum of cHAP calcined at $800{ }^{\circ} \mathrm{C}$ also shown in Fig. 1 shows the characteristic bands of phosphate $\left(\mathrm{PO}_{4}{ }^{3-}\right)$ and carbonate $\left(\mathrm{CO}_{3}{ }^{2-}\right)$ groups. The absorption bands between 1200 and $900 \mathrm{~cm}^{-1}$ are due to the triple degenerated asymmetric stretching mode $\nu_{3}$, and the symmetric stretching mode $\nu_{1}$ of the $\mathrm{P}-\mathrm{O}$ bonds, while bands between 630 and $450 \mathrm{~cm}^{-1}$ are due to the triple degenerated bending mode $\nu_{4}$ of the $\mathrm{O}-\mathrm{P}-\mathrm{O}$ of apatitic $\mathrm{PO}_{4}{ }^{3-}$ groups. Bands in the $1550-1360 \mathrm{~cm}^{-1}$ region are characteristic of $\mathrm{CO}_{3}{ }^{2-}$ groups in the cHAP. ${ }^{57,60}$ The band at $875 \mathrm{~cm}^{-1}$ can be attributed to the $\mathrm{CO}_{3}{ }^{2-}$ group substituted for the $\mathrm{PO}_{4}{ }^{3-}$ group (type B carbonate apatite). ${ }^{61}$ Two distinctive

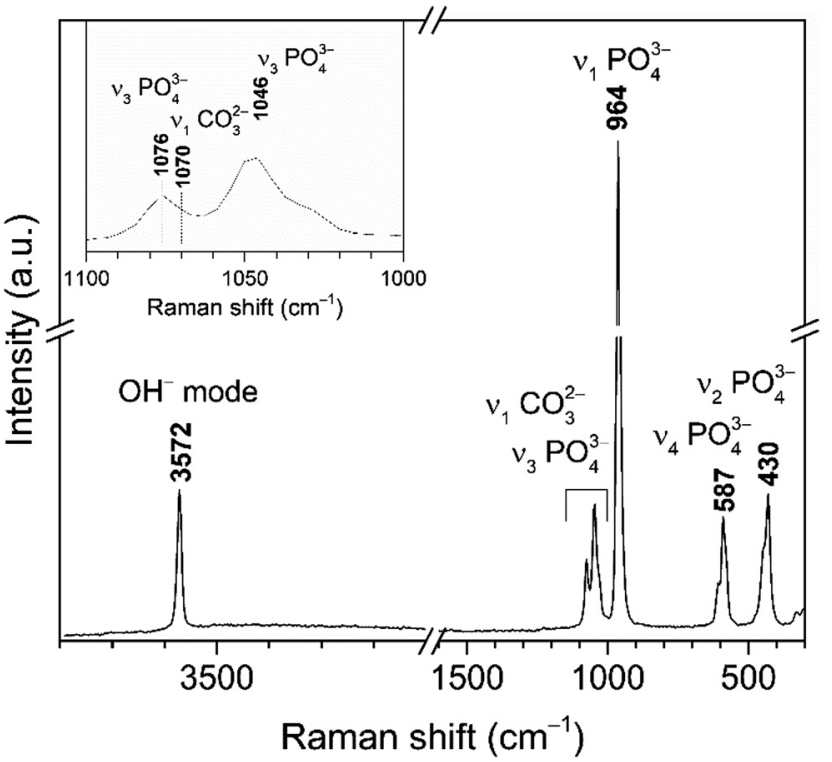

Fig. 3 Raman spectrum of CHAP powders calcined at $800{ }^{\circ} \mathrm{C}$ (inset: enlarged spectrum region of overlapping bands assigned to $\mathrm{PO}_{4}{ }^{3-}$ and $\mathrm{CO}_{3}^{2-}$ modes).

peaks observed at 3571 and $630 \mathrm{~cm}^{-1}$ were assigned to the stretching mode $\nu_{\mathrm{S}}$ and vibrational mode $\nu_{\mathrm{L}}$ respectively of the structural hydroxyl anion $\left(\mathrm{OH}^{-}\right)$in cHAP. Carbonate ions can substitute a hydroxide $\left(\mathrm{OH}^{-}\right)$or phosphate $\left(\mathrm{PO}_{4}{ }^{3-}\right)$ group in the HAP $\left(\mathrm{Ca}_{10}\left(\mathrm{PO}_{4}\right)_{6}(\mathrm{OH})_{2}\right)$ crystal lattice, leading respectively to A- or B-type carbonated apatites. Biological apatite is considered to be an $\mathrm{AB}$ carbonate-substituted apatite. ${ }^{28}$ Studies have shown that cHAP is more soluble in vivo than pure $\mathrm{HAP},{ }^{27,61}$ that it promote cell proliferation, ${ }^{62}$ and that it is therefore likely to lead to an increase in the biological response of the bone mineral while in contact with a cHAP-based scaffold.

Raman spectrum of cHAP powders annealed at $800{ }^{\circ} \mathrm{C}$ is presented in Fig. 3. Characteristic vibrations of the $\mathrm{PO}_{4}{ }^{3-}$ group appears in $1100-1000 \mathrm{~cm}^{-1}$ region and at $964 \mathrm{~cm}^{-1}$ (the most intense band), $587 \mathrm{~cm}^{-1}$ and $430 \mathrm{~cm}^{-1}$. These bands were attributed to the $\nu_{3}\left(\mathrm{PO}_{4}{ }^{3-}\right), \nu_{1}\left(\mathrm{PO}_{4}{ }^{3-}\right), \nu_{4}\left(\mathrm{PO}_{4}{ }^{3-}\right)$ and $\nu_{2}\left(\mathrm{PO}_{4}{ }^{3-}\right)$ modes, respectively. ${ }^{63-65}$ The carbonate band in the Raman spectrum appears at $1070 \mathrm{~cm}^{-1}$; it is quite week and overlaps with bands of the phosphate group (Fig. 3 (inset)). ${ }^{64}$ Furthermore, obtained small band at $326 \mathrm{~cm}^{-1}$ can be assigned to the $\nu_{4}(\mathrm{Ca}-\mathrm{OH})$ mode. ${ }^{65}$ Spectrum also shows the band located at $3572 \mathrm{~cm}^{-1}$ that was assigned to the stretching vibrations of the $\mathrm{O}-\mathrm{H}$ group. The Raman spectrum agrees with the literature and the absence of a splitting in the most intense $\mathrm{PO}_{4}{ }^{3-}$ band indicates a homogeneous carbonate incorporation into the HAP lattice.

\subsection{Acrylate-gelatin-cHAP composite}

The $w t \%$ of cHAP and the distribution of apatite within the polymer matrix were evaluated by thermal analysis. TG, DTG and DSC curves of the acrylate(75\%)-gelatin(25\%)-cHAP composite are presented in Fig. 4, where the decomposition curves show four steps leaving about $37 \%$ residue at about $680{ }^{\circ} \mathrm{C}$. The first weight loss of $\sim 2 \%$ was observed at temperatures up to 


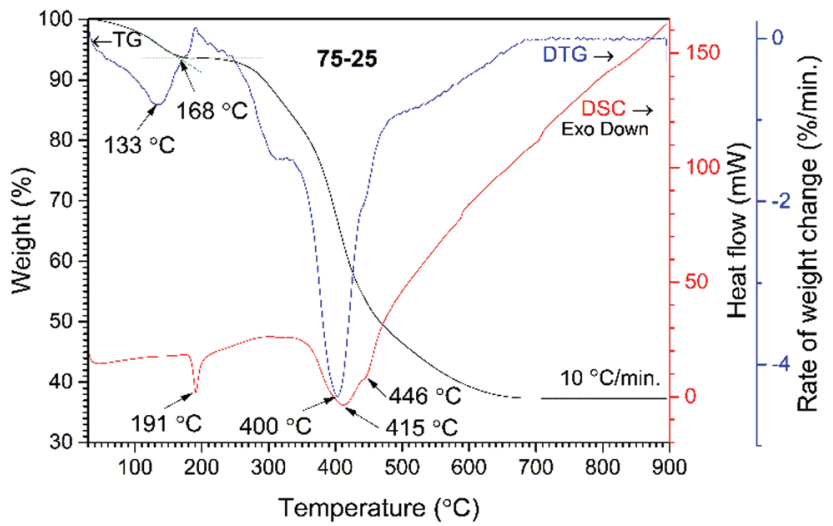

Fig. 4 TG/DTG and DSC curves of acrylate(75\%)-gelatin(25\%)-cHAP composite.

$100{ }^{\circ} \mathrm{C}$ and was attributed to the evaporation of adsorbed water. A weight loss of $\sim 3 \%$ occurred upon further heating up to $200{ }^{\circ} \mathrm{C}$ with an exothermic peak at $\sim 191{ }^{\circ} \mathrm{C}$. This loss was attributed to the initial degradation of the less thermally stable gelatin, as $\mathrm{N}$-terminal residues are released before the complete separation as free amino acids, as well as polymer-bound water. ${ }^{66}$ The third and fourth overlapped steps represent a sequence of pyrolytic reactions. The first weight loss of $\sim 15 \%$ takes place at temperatures up to $400{ }^{\circ} \mathrm{C}$ and can be assigned to the partial decomposition of organic compounds (gelatin, acrylate) and the removal of $\mathrm{CO}_{2}$. Such processes are seen in the DTG curve where broad overlapping peaks with maxima at 320 and $400{ }^{\circ} \mathrm{C}$ occur. Heating to $650{ }^{\circ} \mathrm{C}$ led to a further $42 \%$ decrease in weight with a broad exothermic peak (max at 415 and $446{ }^{\circ} \mathrm{C}$ ) and this was attributed to the decomposition of organic compounds, and to the removal of lattice water and carbonates from cHAP, as these processes occur at about $600{ }^{\circ} \mathrm{C}$. ${ }^{63}$ The acrylate(50\%)-gelatin(50\%)-cHAP and acrylate(95\%)-gelatin(5\%)-cHAP composites exhibited similar decomposition behaviour (data not presented).

The presence of prominent components within the multicomposite scaffolds was confirmed by FTIR spectroscopy, where the IR spectrum of the representative acrylate(75\%)gelatin(25\%)-cHAP composite scaffold shown in Fig. 5 exhibits characteristic bands assigned to acrylate, cHAP and gelatin. The absorption bands at 1089, 1024, 962 and $629 \mathrm{~cm}^{-1}$ were assigned to the cHAP. The spectral features of the apatite do not appear to have changed after it was incorporated into the polymeric matrix. The spectrum of the multi-composite also shows a wide band in the $1730-1700 \mathrm{~cm}^{-1}$ region which can be ascribed to the carbonyl $(\mathrm{C}=\mathrm{O})$ group stretching vibrations of acrylate. ${ }^{67,68}$ The important peaks for $\mathrm{C}=\mathrm{C}$ deformation of the acrylate group appear at 1636, 1408 and $809 \mathrm{~cm}^{-1}$, and this indicates that some residual $\mathrm{C}=\mathrm{C}$ bonds remain inside the network structure. The copolymerization of DPHA and EGDMA monomers under UV irradiation is a free radical chain growth cross-linking reaction that is diffusion-controlled. The molar ratios of $\mathrm{C}=\mathrm{C}$ bonds in the different monomers, the concentration of initiator, the curing times, and the reaction temperatures affect the
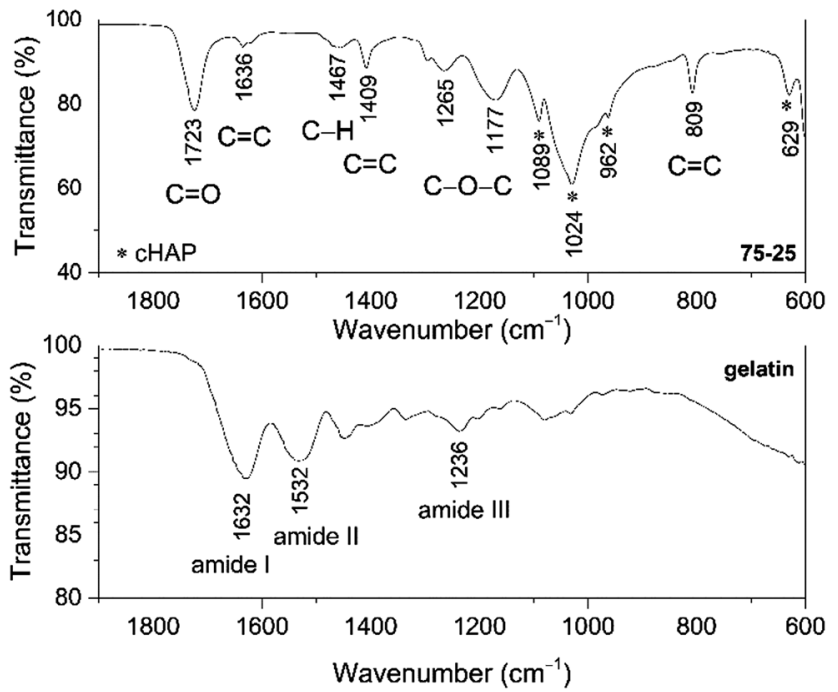

Fig. 5 FT-IR spectra of the acrylate-gelatin(75\%)-cHAP(25\%) composite and neat gelatin powders.

reaction kinetics and products. Although the formation of a crosslinked structure reduces the termination rate of free radicals, it also reduces the diffusion of reactants in the later stages of the reaction, so the final conversion is limited. ${ }^{69}$ The relative intensities of the $1636 \mathrm{~cm}^{-1}\left(\mathrm{C}=\mathrm{C}\right.$ stretching) and $1723 \mathrm{~cm}^{-1}$ $(\mathrm{C}=\mathrm{O}$ stretching) peaks nevertheless indicate that the monomers were consumed during curing and that a highly crosslinked network was created. The simplified intermolecular crosslinking of monomers DPHA and EGDMA under UV irradiation is shown in Fig. 6.

Furthermore, the spectrum of pure gelatin in Fig. 5 exhibits absorption bands in the 1700-1600, 1565-1520 and 1280-1230 cm regions, and these are characteristic vibrations arising from amide I, amide II and amide III, respectively. ${ }^{70}$ It can be seen that the bands attributed to amide I and amide II exhibit different spectral features in the spectrum of the multi-composite scaffold, and that the broad band of amide III is absent, indicating some structural changes. Similar spectral features were observed in a related study where the interactions of calcium phosphate as an inorganic phase within an organic matrix were studied. ${ }^{71,72}$

Several other peaks in the spectrum of the composite can be observed at $\sim 1460 \mathrm{~cm}^{-1}$ attributed to the $\mathrm{C}-\mathrm{H}$ vibrations, while broad bands at $1265 \mathrm{~cm}^{-1}$ and $1180 \mathrm{~cm}^{-1}$ are due to $\mathrm{C}-\mathrm{O}-\mathrm{C}$ stretching moieties of the acrylate. ${ }^{73}$

\subsection{Surface morphology}

Fig. 7 shows FE-SEM images of a representative acrylate(75\%)gelatin(25\%)-cHAP composite that on a macroscale (left) the composite surface is rather uneven, but a higher magnification (right) shows that the cHAP particles are homogeneously imbedded in the continuous polymeric matrix. Voids and large agglomerate blocks were also observed on parts of the composite pellets. The cHAP-acrylate(50\%)-gelatin(50\%) composites exhibited a slightly rougher surface, possibly due to the higher cHAP concentration. Fig. 8 shows SEM images and corresponding 


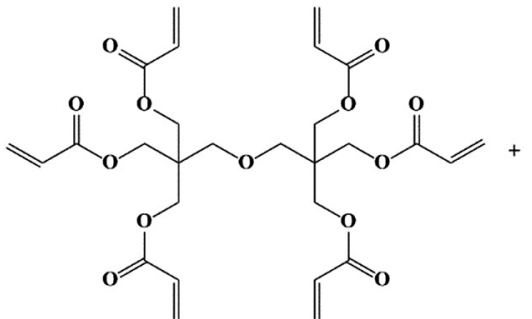

DPHA

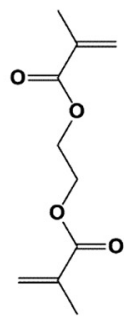

EGDMA

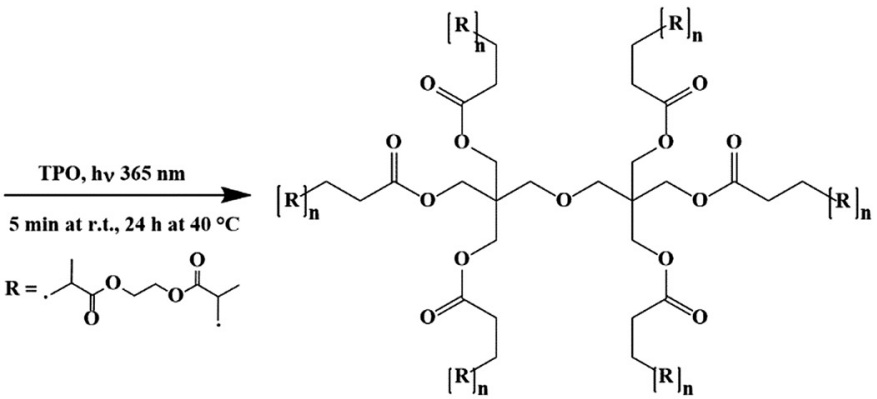

Fig. 6 Simplified intermolecular cross-linkage of monomers DPHA and EGDMA under UV irradiation.

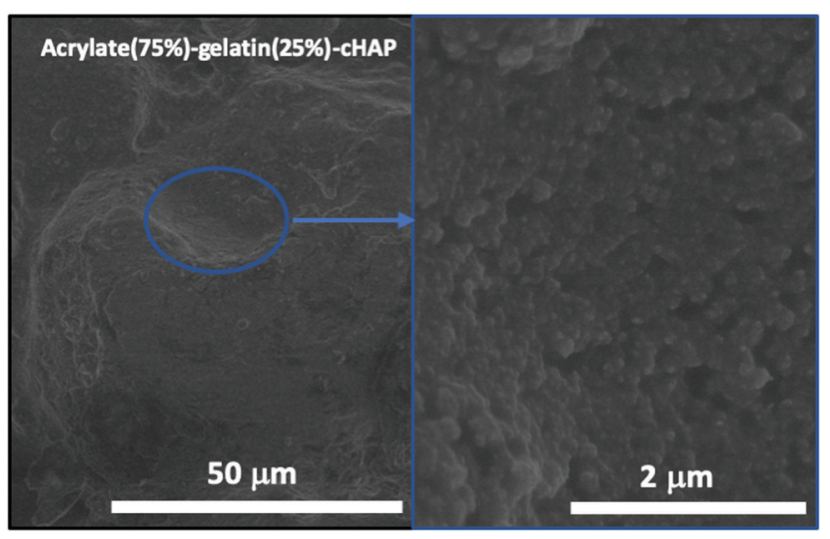

Fig. 7 FE-SEM images of the surface of acrylate(75\%)-gelatin(25\%)-cHAP composite.

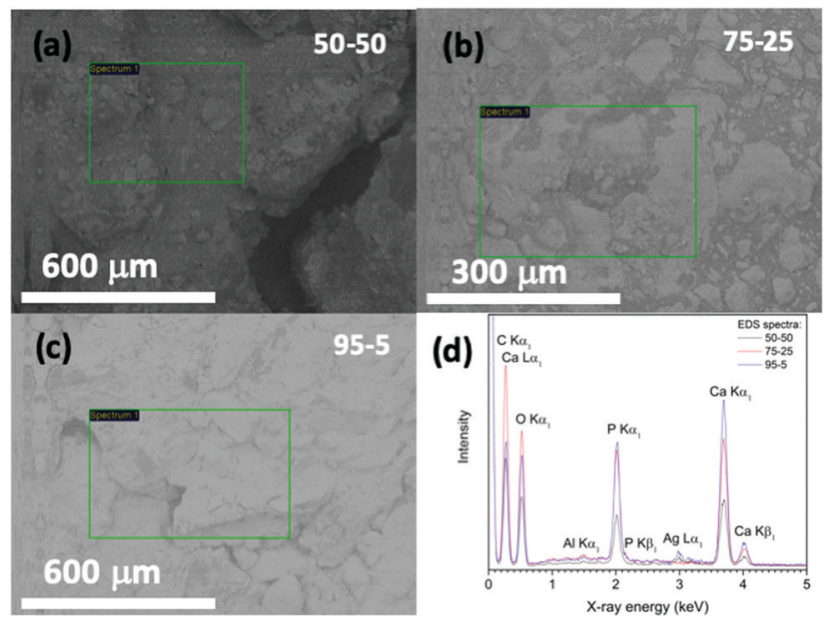

Fig. 8 (a-c) SEM images (marked places show the surface regions examined) and (d) EDS spectra of acrylate-gelatin-cHAP composite scaffolds.

EDS spectra of the multi-composites. The 50/50 composite shows voids with a width of $300 \mu \mathrm{m}$. Elements $\mathrm{C}, \mathrm{O}, \mathrm{P}$ and $\mathrm{Ca}$ were detected. $\mathrm{Al}$ and $\mathrm{Ag}$ were also detected, but these were due to the sample holder and pre-sputtering, respectively. The average atomic\% ratio of $\mathrm{Ca} / \mathrm{P}$ was calculated to be $1.6(n=11)$ and place dependency was revealed. In the nonstoichiometric apatites, the $\mathrm{Ca} / \mathrm{P}$ ratio depends on the ionic substitution in the crystal lattice.
That is, when $\mathrm{PO}_{4}{ }^{3-}$ ions are replaced by $\mathrm{CO}_{3}{ }^{2-}$ ions (B-substitution), the $\mathrm{Ca} / \mathrm{P}$ ratio is larger than that of stoichiometric HAP, and when $\mathrm{OH}^{-}$ions in the apatite structure are replaced by $\mathrm{CO}_{3}{ }^{2-}$ ions (A-type substitution) or $\mathrm{HPO}_{4}{ }^{3-}$ ions replace $\mathrm{PO}_{4}{ }^{3-}$ the $\mathrm{Ca} / \mathrm{P}$ ratio tends to be smaller than $1.67 .{ }^{57,74}$ Other composites exhibited similar morphological features.

\subsection{Computed tomography (CT)}

Computed tomography (CT) was used to assess the density of the scaffolds. The cross-sectional CT images of acrylate-gelatin-cHAP scaffolds (scan performed at $80 \mathrm{kV}$ ) presented in Fig. 9 (inset: camera photos of scaffolds) shows that the scaffolds with different compositions had different densities. The average density was calculated to be 1863,2171 and $2224 \mathrm{~kg} \mathrm{~m}^{-3}$ for the 50/50, 75/25 and 95/5 composite scaffolds, respectively. The difference in density is mainly due to a difference in material composition, but the density varied slightly within the specimen, the material density being higher in the central region than in the outer layer. The density values of the multi-composites were not changed when scan was performed at $110 \mathrm{kV}$. A number of bonescaffold features affect scaffold resorption, cell penetration and the ingrowth of new bone. ${ }^{75-77}$ Since the porosity of the material is related to its density, the rate of dissolution of surface components, the formation of voids within the scaffold, and the penetration of liquid phase into the inner layers of the composite can be predicted. Thus, the 50/50 multi-composite scaffolds probably have the fastest degradation and the greatest formation of voids within the scaffold when it is in contact with a liquid phase. Due to the higher atomic numbers of the elements, the ceramic material attenuates the X-ray beam more than the acrylate/gelatin matrix, but the internal microstructure of the composites was not resolved due to the lower resolution of the medical CT scanner compared to that of other (microand nano-) CT devices. ${ }^{78}$ Extensive studies have demonstrated the micro-CT can reveal bone tissue density as well as new bone formation throughout the depth of the scaffolds, ${ }^{51-53,79}$ although the use of contrast agents or a complementary technique such as MRI may be needed. ${ }^{80}$

To obtain more complete characterization in assessing inner architecture of scaffolds, a cone beam computed tomography (CBCT) analysis was performed. Fig. 10(a) shows CBCT image of 50/50, 75/25 and 95/5 composites as well as segmented images (6 of total 24) of multiple projections of the 95/5 composite. 

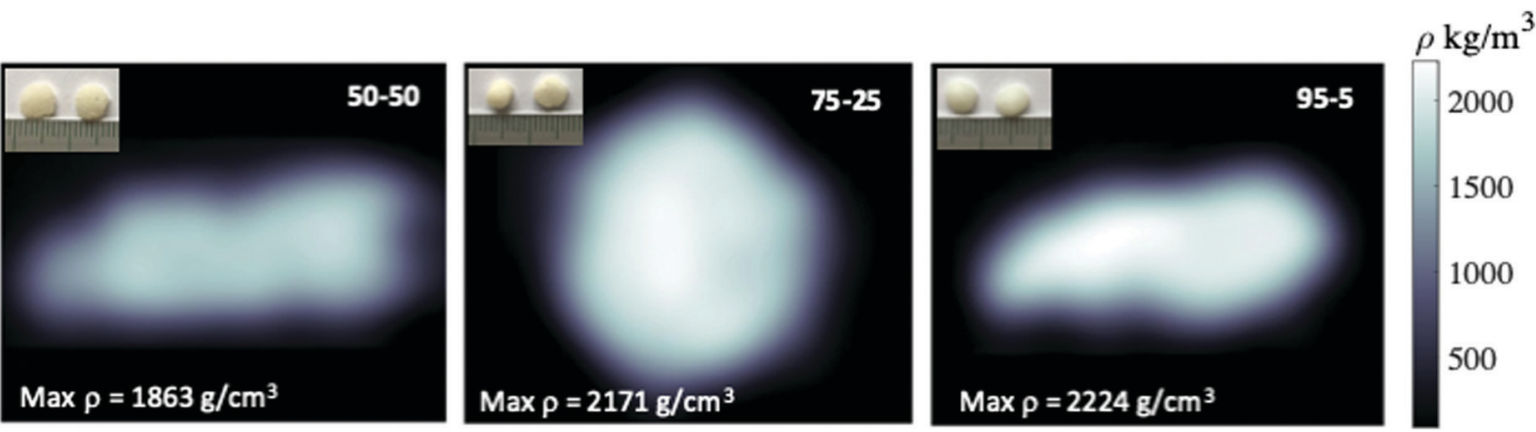

Fig. 9 Cross-sectional CT images of the acrylate-gelatin-cHAP composites and the calculated density (inset: photographs of composites placed on the ruler, scale: $1 \mathrm{bar}=1 \mathrm{~mm}$ ). The 50/50 and 95/5 composites were scanned in the radial direction and the 75/5 composite in the axial direction (X-ray beam energy of $80 \mathrm{kV}$ ).

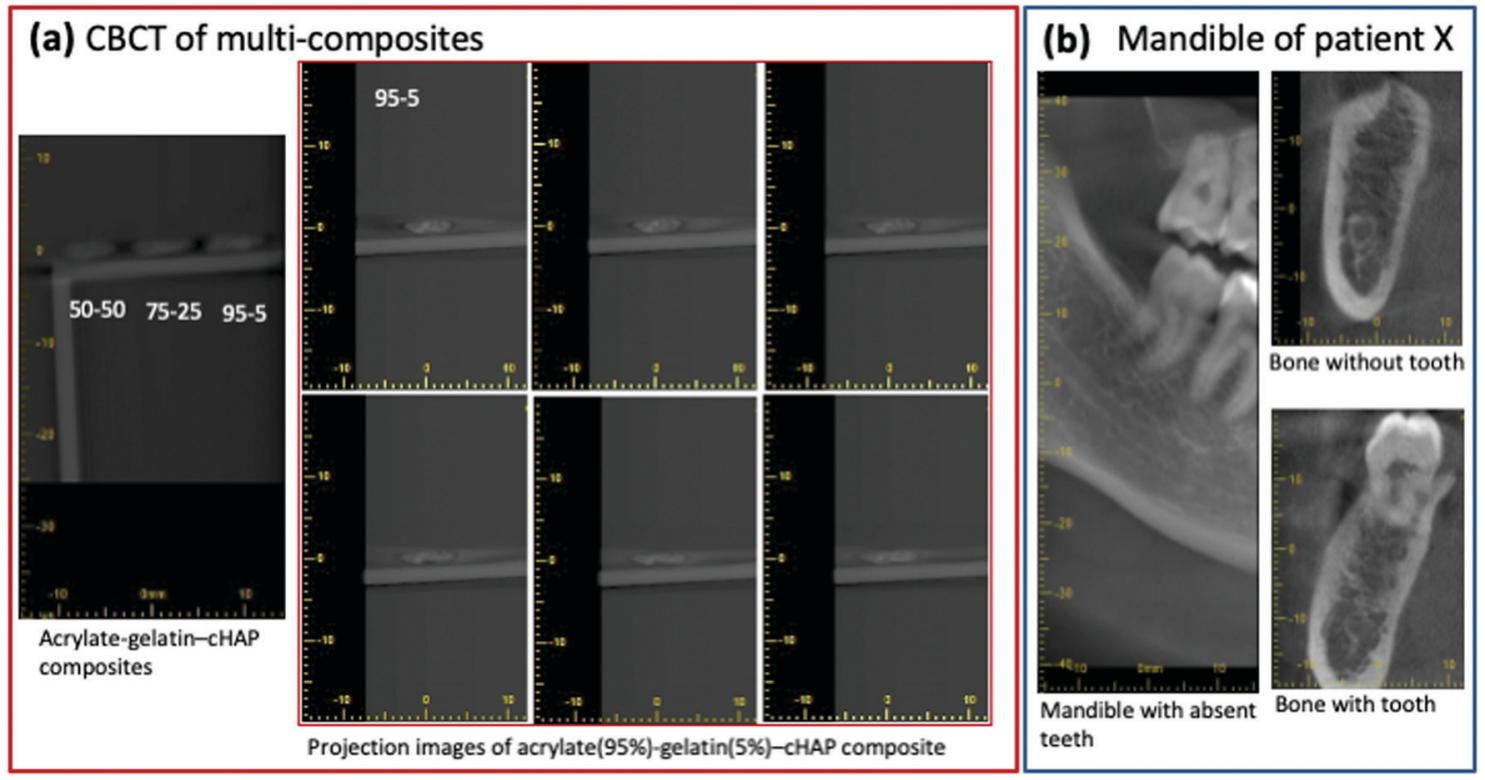

Fig. $10 \mathrm{CBCT}$ images of (a) acrylate-gelatin-cHAP composites and traversing images (6 of total 24) of multiple projections of the $95 / 5$ composite, (b) orofacial region of patient $\mathrm{X}$ showing radiographic contrast between different bone tissues (CBCT was performed under the same conditions to compare the radiographic contrast).

Data demonstrate that radiographic contrast of the images is higher. Composite, although mostly radiolucent, it also contains apatite particles that are radiopaque. Some fogging in the images of the composites is also present and this was attributed to the scattered X-ray radiation. To compare a subject contrast, the mandible (lower jaw) images of patient $\mathrm{X}$ are presented in Fig. 10(b). These intraoral CBCT images were taken under the same conditions as fabricated scaffolds. Comparison of images show that dental bone exhibits higher contrast indicating that fabricated multi-composites could be more easily distinguished after the implantation while observing anatomic structures of interest.

\subsection{Conventional radiography}

To further evaluate structural features of the scaffolds, conventional dental radiography was used, as shown in Fig. 11 which presents a radiographic image of a representative acrylate(75\%)-gelatin(25\%)cHAP scaffold. Composite is as a restorative material and their radiographic appearance vary depending on their thickness,

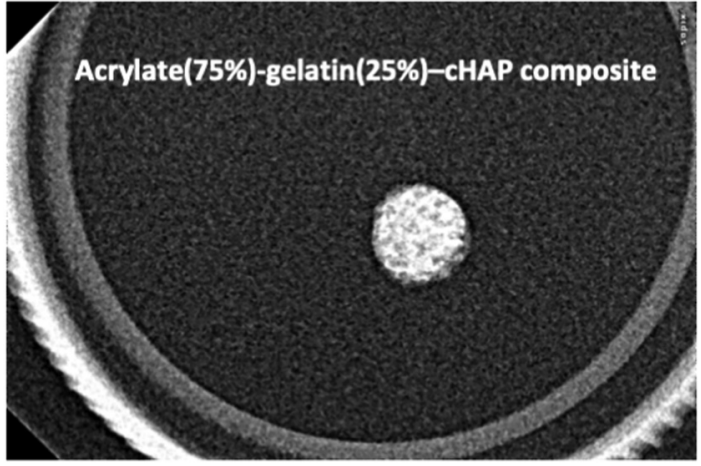

Fig. $11 X$-ray radiograph of the representative acrylate(75\%)-gelatin(25\%)cHAP composite scaffold showing the distribution of cHAP (brighter places) within the organic matrix.

density, and atomic number. Due to its higher radiological density compared to that of the organic matrix, the apatitic phase is clearly visible with a homogeneous distribution of the 
cHAP over the entire scaffold. This indicates the possibilities of achieving radiographic differentiation between the bone tissue and the restorative scaffold and of evaluating structural changes when it is replaced by de novo bone. ${ }^{81,82}$

\subsection{Surface hydrophilicity}

The wettability of the scaffolds was assessed by measuring the contact angle of water tinted with methylene blue dye which is frequently used as a cationic stain to examine cytological specimens. $^{35,82}$ The sessile drop contact angles are presented as function of time in Fig. 12. Within a few seconds, the contact angle on all the scaffolds decreased by $15-20^{\circ}$ (initial average angles of $91^{\circ}, 100^{\circ}$ and $67^{\circ}$ were measured for the 50/50, 75/25 and $95 / 5$ composites, respectively) $(n=3)$. The angle then gradually decreased more slowly until it reached a plateau. The final values after 60 seconds were $47.6^{\circ}$ and $31.4^{\circ}$ for the 50/50 and 95/5 composites, respectively. The 75/5 composite however exhibited a slightly different behaviour. After the initial decrease, the contact angle decreased relatively rapidly from $63.4^{\circ}$ to $21.5^{\circ}$ (within $15 \mathrm{~s}$ ) and then continued to decline until the final angle after 50 seconds was found to be $16.6^{\circ}$, indicating that this was the most hydrophilic surface investigated. These differences in the contact angle were attributed to differences in surface morphology (Fig. 7 and 8) which depend on the composition. The surface characteristics, such as the porosity (pore diameter, interconnectedness, pore orientation), roughness and topography as well as chemistry (element present, presence of polar/non-polar group, acid-base characteristics, dangling bonds), have a great effect on the hydrophilicity and subsequently bioactivity. ${ }^{83,84}$

The rates of degradation of DPHA, EGDMA and gelatin differ, and the combination of DPHA/EGDMA, gelatin and cHAP in bone tissue engineering can therefore provide some advantages, as the composites may degrade faster than a pure acrylate-based polymer matrix. The hydrophilicity of the bioceramic and

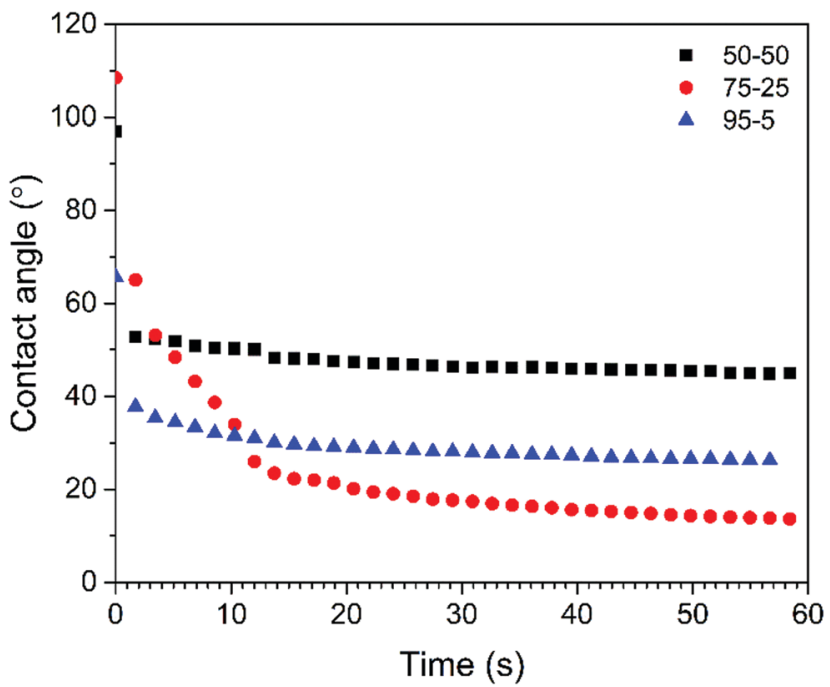

Fig. 12 Contact angles vs. time (sessile drop of water tinted with methylene blue dye) on acrylate-gelatin-cHAP composite scaffolds (values of the first measurement are presented). gelatin should enable water to penetrate more easier into the acrylate-based matrix and thus promote hydrolytic degradation where scaffolds and body fluids interact, and the microstructural architecture of the scaffold could enhance the mineralization of new bone in the interior of the composite material and allow deeper tissue ingrowth.

The favourable properties of the acrylate-gelatin-cHAP composites made by the approach described here may extend the potential for porosity as well as hydrophilicity remodelling, and promote scaffold-implant integration. These applications are presently under investigation.

\section{Conclusions}

In this work, carbonated hydroxyapatite (cHAP) was synthesized by precipitation and annealing at $800{ }^{\circ} \mathrm{C}$. XRD analysis showed that the cHAP powders were a phase pure, having a crystallite size of $32 \mathrm{~nm}$. FTIR studies confirmed that AB-substituted cHAP was synthesized. Raman studies and Rietveld analysis revealed the homogeneous carbonate substitution throughout the HAP lattice. Multi-composites consisting of acrylate (DPHA/EGDMA), cHAP and gelatin were successfully prepared via copolymerization. Morphological studies revealed that cHAP particles were homogeneously imbedded within the continuous polymeric matrix, and that the scaffolds possessed voids and large agglomerate blocks in different parts of the composite pellets. TG analysis confirmed that the residual inorganic material mass corresponded well with the initial quantity of cHAP. CT analysis showed that the scaffolds had differing average densities and that the scaffolds had a higher density in the central region than in the outer layer. CBCT analysis revealed that dental bone exhibits higher radiographic contrast than fabricated multi-composites, and so indicate easier identification after the implantation while observing anatomic structures of interest. Conventional radiography images further validated cHAP, exhibiting higher radiographic density compared to organic matrix, and homogeneous distribution within the entire scaffold. Contact angle measurements revealed that the hydrophilicity was composition- and morphology-dependent, the greatest wettability of $16.6^{\circ}$ being on the acrylate(75\%)-gelatin(25\%)cHAP composite scaffold. The favourable properties of the composites fabricated using the approach described here may have potential in porosity and hydrophilicity remodelling strategies, and subsequently promote scaffold-implant integration.

\section{Conflicts of interest}

There are no conflicts to declare.

\section{Acknowledgements}

The computed tomography studies using a CT-scanner (Siemens Somatom Emotion Duo) were supported by FORMAS grant (No. 2018-01198). Dr Ramunas Skaudzius is acknowledged for helping with Rietveld analysis. 


\section{References}

1 Global data: Dental Bone Grafts \& Substitutes Market Analysis Report by Material Type (Allograft, Xenograft, Synthetic), by Application (Sinus Lift, Ridge Augmentation), by End Use (Hospitals, Dental Clinics), and Segment Forecast, 2019-2026; Publisher: Grand View Research (SKU: GV16142504), 2019, December, Retrieved from: https:// www.marketresearch.com/Grand-View-Research-v4060/DentalBone-Grafts-Substitutes-Material-12964345/.

2 L. Polo-Corrales, M. Latorre-Esteves and J. E. Ramirez-Vick, Nanosci. Nanotechnol., 2014, 14, 15-56.

3 L.-P. Yan, J. M. Oliveira, A. L. Oliveira and R. L. Reis, ACS Biomater. Sci. Eng., 2015, 1, 183-200.

4 M. M. Stevens, Mater. Today, 2008, 11, 18-25.

5 K. Rezwan, Q. Z. Chen, J. J. Blaker and A. R. Boccaccini, Biomaterials, 2006, 27, 3413-3431.

6 Y. Du, J. L. Guo, J. Wang, A. G. Mikos and S. Zhang, Biomaterials, 2019, 218, 119334.

7 B. Conrad, C. Hayashi and F. Yang, ACS Biomater. Sci. Eng., 2020, 6, 3454-3463.

8 G. Fernandez de Grado, L. Keller, Y. Idoux-Gillet, Q. Wagner, A.-M. Musset, N. Benkirane-Jessel, F. Bornert and D. Offner, J. Tissue Eng., 2018, 9, 1-18.

9 A. R. Amini, C. T. Laurencin and S. P. Nukavarapu, Crit. Rev. Biomed. Eng., 2012, 40, 363-408.

10 E. García-Gareta, M. J. Coathup and G. W. Blunn, Bone, 2015, 81, 112-121.

11 H. J. Haugen, S. P. Lyngstadaas, F. Rossi and G. Perale, J. Clin. Periodontol., 2019, 46, 92-102.

12 Z. Hao, Z. Song, J. Huang, K. Huang, A. Panetta, Z. Gu and J. Wu, Biomater. Sci., 2017, 5, 1382-1392.

13 G. Narayanan, V. N. Vernekar, E. L. Kuyinu and C. T. Laurencin, Adv. Drug Delivery Rev., 2016, 107, 247-276.

14 Y. Jung, M. S. Park, J. W. Lee, Y. H. Kim, S.-H. Kim and S. H. Kim, Biomaterials, 2008, 29, 4630-4636.

15 J. Zhang, S. Yang, X. Yang, Z. Xi, L. Zhao, L. Cen, E. Lu and Y. Yang, ACS Biomater. Sci. Eng., 2018, 4, 694-706.

16 A. Fottner, B. Nies, D. Kitanovic, A. Steinbrück, S. MayerWagner, C. Schröder, S. Heinemann, U. Pohl and V. Jansson, J. Mater. Sci.: Mater. Med., 2016, 27, 138.

17 J. C. J. Webb and R. F. Spencer, J. Bone Jt. Surg., Br. Vol., 2007, 89B, 851-857.

18 P. Gentile, V. Chiono, I. Carmagnola and P. V. Hatton, Int. J. Mol. Sci., 2014, 15, 3640-3659.

19 J. J. Chung, S. Li, M. M. Stevens, T. K. Georgiou and J. R. Jones, Chem. Mater., 2016, 28, 6127-6135.

20 F. Donnaloja, E. Jacchetti, M. Soncini and T. M. Raimondi, Polymers, 2020, 12, 905-932.

21 R. Zhang and P. X. Ma, J. Biomed. Mater. Res., 1999, 45, 285-293.

22 J. E. Devin, M. A. Attawia and C. T. Laurencin, J. Biomater. Sci., Polym. Ed., 1996, 7, 661-669.

23 K. Yoshihara, N. Nagaoka, S. Hayakawa, T. Okihara, Y. Yoshida and B. Van Meerbeek, Dent. Mater., 2018, 34, 1072-1081.

24 S. E. Lobo and T. L. Arinzeh, Materials, 2010, 3, 815-826.
25 R. Z. LeGeros, S. Lin, R. Rohanizadeh, D. Mijares and J. P. LeGeros, J. Mater. Sci.: Mater. Med., 2003, 14, 201-209.

26 G. Wang, Z. Lu, X. Zhao, A. Kondyurin and H. Zreiqat, J. Mater. Chem. B, 2013, 1, 2455-2462.

27 Y. Doi, T. Shibutani, Y. Moriwaki, T. Kajimoto and Y. Iwayama, J. Biomed. Mater. Res., 1998, 39, 603-610.

28 E. Boanini, M. Gazzano and A. Bigi, Acta Biomater., 2010, 6, 1882-1894.

29 H. H. Xu and C. G. Simon, Jr., J. Biomed. Mater. Res., Part A, 2004, 69, 267-278.

30 H. Shen, X. Hu, F. Yang, J. Bei and S. Wang, Biomaterials, 2007, 28, 4219-4230.

31 L. Zhu, D. Luo and Y. Liu, Int. J. Oral Sci., 2020, 12, 6.

32 M. Costantini and A. Barbetta, in Functional 3D Tissue Engineering Scaffolds, ed. Y. Deng and J. Kuiper, Woodhead Publishing, 2018, pp. 127-149, DOI: 10.1016/B978-0-08100979-6.00006-9.

33 W. Chen, H. Zhou, M. Tang, M. D. Weir, C. Bao and H. H. K. Xu, Tissue Eng., Part A, 2012, 18, 816-827.

34 S. Hesaraki, F. Moztarzadeh and D. Sharifi, J. Biomed. Mater. Res., Part A, 2007, 83, 80-87.

35 P. Habibovic, H. Yuan, C. M. van der Valk, G. Meijer, C. A. van Blitterswijk and K. de Groot, Biomaterials, 2005, 26, 3565-3575.

36 A. Barbetta, M. Dentini, E. M. Zannoni and M. E. De Stefano, Langmuir, 2005, 21, 12333-12341.

37 M. Schardosim, J. Soulié, D. Poquillon, S. Cazalbou, B. Duployer, C. Tenailleau, C. Rey, R. Hübler and C. Combes, Mater. Sci. Eng., C, 2017, 77, 731-738.

38 A. Lee, C. R. Langford, L. M. Rodriguez-Lorenzo, H. Thissen and N. R. Cameron, Biomater. Sci., 2017, 5, 2035-2047.

39 I. K. Januariyasa, I. D. Ana and Y. Yusuf, Mater. Sci. Eng., C, 2020, 107, 110347.

40 I. Gendviliene, E. Simoliunas, S. Rekstyte, M. Malinauskas, L. Zaleckas, D. Jegelevicius, V. Bukelskiene and V. Rutkunas, J. Mech. Behav. Biomed. Mater., 2020, 104, 103616.

41 J. Lee and G. Kim, ACS Biomater. Sci. Eng., 2018, 4, 278-289. 42 Y. Luo, Y. Li, X. Qin and Q. Wa, Mater. Des., 2018, 146, 12-19.

43 C. Shuai, B. Yang, S. Peng and Z. Li, Int. J. Adv. Des. Manuf. Technol., 2013, 69, 51-57.

44 D. Miranda-Nieves and E. L. Chaikof, ACS Biomater. Sci. Eng., 2017, 3, 694-711.

45 P. Zhai, X. Peng, B. Li, Y. Liu, H. Sun and X. Li, Int. J. Biol. Macromol., 2020, 151, 1224-1239.

46 A. M. Ferreira, P. Gentile, V. Chiono and G. Ciardelli, Acta Biomater., 2012, 8, 3191-3200.

47 S. Ber, G. Torun Köse and V. Hasırcı, Biomaterials, 2005, 26, 1977-1986.

48 P. S. Kowalski, C. Bhattacharya, S. Afewerki and R. Langer, ACS Biomater. Sci. Eng., 2018, 4, 3809-3817.

49 M. C. Gómez-Guillén, B. Giménez, M. E. López-Caballero and M. P. Montero, Food Hydrocoll., 2011, 25, 1813-1827.

50 A. K. Teotia, A. Gupta, D. B. Raina, L. Lidgren and A. Kumar, ACS Appl. Mater. Interfaces, 2016, 8, 10775-10787.

51 M. Mashiatulla, R. D. Ross and D. R. Sumner, Bone, 2017, 99, 53-61. 
52 J. R. Jones, G. Poologasundarampillai, R. C. Atwood, D. Bernard and P. D. Lee, Biomaterials, 2007, 28, 1404-1413.

53 A. C. Jones, C. H. Arns, A. P. Sheppard, D. W. Hutmacher, B. K. Milthorpe and M. A. Knackstedt, Biomaterials, 2007, 28, 2491-2504.

54 A. J. Wagoner Johnson and B. A. Herschler, Acta Biomater., 2011, 7, 16-30.

55 S. Weiner and H. D. Wagner, Annu. Rev. Mater. Sci., 1998, 28, 271-298.

56 G. J. Kazakia, A. J. Burghardt, S. Cheung and S. Majumdar, Med. Phys., 2008, 35, 3170-3179.

57 E. Garskaite, L. Alinauskas, M. Drienovsky, J. Krajcovic, R. Cicka, M. Palcut, L. Jonusauskas, M. Malinauskas, Z. Stankeviciute and A. Kareiva, $R S C$ Adv., 2016, 6, 72733-72743.

58 W. Huda, E. M. Scalzetti and G. Levin, Radiology, 2000, 217, 430-435.

59 M. Jevtić, M. Mitrić, S. Škapin, B. Jančar, N. Ignjatović and D. Uskoković, Cryst. Growth Des., 2008, 8, 2217-2222.

60 R. Golubevas, A. Zarkov, L. Alinauskas, Z. Stankeviciute, G. Balciunas, E. Garskaite and A. Kareiva, RSC Adv., 2017, 7, 33558-33567.

61 M. Hasegawa, Y. Doi and A. Uchida, J. Bone Jt. Surg., Br. Vol., 2003, 85-B, 142-147.

62 M.-M. Germaini, R. Detsch, A. Grünewald, A. Magnaudeix, F. Lalloue, A. R. Boccaccini and E. Champion, Biomed. Mater., 2017, 12, 035008.

63 E. Garskaite, K.-A. Gross, S.-W. Yang, T. C.-K. Yang, J.-C. Yang and A. Kareiva, CrystEngComm, 2014, 16, 3950-3959.

64 F. F. de Mul, M. H. Hottenhuis, P. Bouter, J. Greve, J. Arends and J. J. ten Bosch, J. Dent. Res., 1986, 65, 437-440.

65 M. P. M. Marques, A. P. Mamede, A. R. Vassalo, C. Makhoul, E. Cunha, D. Gonçalves, S. F. Parker and L. A. E. Batista de Carvalho, Sci. Rep., 2018, 8, 15935.

66 A. A. Apostolov, S. Fakirov, E. Vassileva, R. D. Patil and J. E. Mark, J. Appl. Polym. Sci., 1999, 71, 465-470.

67 A. Tuncel and E. Pişkin, J. Appl. Polym. Sci., 1996, 62, 789-798.

68 M. U. Minhas, M. Ahmad, J. Anwar and S. Khan, Adv. Polym. Technol., 2018, 37, 221-229.
69 C.-W. Huang, Y.-M. Sun and W.-F. Huang, J. Polym. Sci., Part A: Polym. Chem., 1997, 35, 1873-1889.

70 N. Cebi, M. Z. Durak, O. S. Toker, O. Sagdic and M. Arici, Food Chem., 2016, 190, 1109-1115.

71 R. W. Arcís, A. López-Macipe, M. Toledano, E. Osorio, R. Rodríguez-Clemente, J. Murtra, M. A. Fanovich and C. D. Pascual, Dent. Mater., 2002, 18, 49-57.

72 S. W. Xu, J. P. Zheng, L. Tong and K. D. Yao, J. Appl. Polym. Sci., 2006, 101, 1556-1561.

73 H. A. Willis, V. J. I. Zichy and P. J. Hendra, Polymer, 1969, 10, 737-746.

74 A. Yasukawa, K. Kandori and T. Ishikawa, Calcif. Tissue Int., 2003, 72, 243-250.

75 P. S. P. Poh, D. Valainis, K. Bhattacharya, M. van Griensven and P. Dondl, Sci. Rep., 2019, 9, 9170.

76 A. Cipitria, C. Lange, H. Schell, W. Wagermaier, J. C. Reichert, D. W. Hutmacher, P. Fratzl and G. N. Duda, J. Bone Miner. Res., 2012, 27, 1275-1288.

77 A. Petersen, A. Princ, G. Korus, A. Ellinghaus, H. Leemhuis, A. Herrera, A. Klaumünzer, S. Schreivogel, A. Woloszyk, K. Schmidt-Bleek, S. Geissler, I. Heschel and G. N. Duda, Nat. Commun., 2018, 9, 4430.

78 M. Kampschulte, A. C. Langheinirch, J. Sender, H. D. Litzlbauer, U. Althohn, J. D. Schwab, E. Alejandre-Lafont, G. Martels and G. A. Krombach, Rofo-Fortschr. Rontg., 2016, 188, 146-154.

79 L. Borkowski, A. Sroka-Bartnicka, I. Polkowska, M. Pawlowska, K. Palka, E. Zieba, A. Slosarczyk, K. Jozwiak and G. Ginalska, Anal. Bioanal. Chem., 2017, 409, 5747-5755.

80 K. D. Novakofski, S. L. Pownder, M. F. Koff, R. M. Williams, H. G. Potter and L. A. Fortier, Cartilage, 2016, 7, 39-51.

81 N. A. Kotnis, N. Parasu, K. Finlay, E. Jurriaans and M. Ghert, Skeletal Radiol., 2011, 40, 563-570.

82 R. Duan, D. Barbieri, F. de Groot, J. D. de Bruijn and H. Yuan, ACS Biomater. Sci. Eng., 2018, 4, 3347-3355.

83 V. Karageorgiou and D. Kaplan, Biomaterials, 2005, 26, 5474-5491.

84 M. J. Dalby, L. Di Silvio, E. J. Harper and W. Bonfield, Biomaterials, 2002, 23, 569-576. 